\title{
Double blind glucocorticoid controlled trial of samarium-153 particulate hydroxyapatite radiation synovectomy for chronic knee synovitis
}

\author{
E K O’Duffy, G P R Clunie, D Lui, J C W Edwards, P J Ell
}

\begin{abstract}
Background-Samarium-153 particulate hydroxyapatite (Sm-153 PHYP) is a relatively new radiation synovectomy agent developed for the treatment of chronic synovitis. Although it has been shown that the levels of unwanted extra-articular radiation are lower after intra-articular injection of Sm-153 PHYP than yttrium-90 colloid, its clinical efficacy has not been rigorously studied.
\end{abstract}

Objectives-To establish whether Sm-153 PHYP radiation synovectomy results in a clinically useful benefit sustained at one year.

Methods-In a randomised double blind study, patients received either intraarticular $40 \mathrm{mg}$ triamcinolone hexacetonide alone or $40 \mathrm{mg}$ triamcinolone hexacetonide combined with Sm-153 PHYP in an outpatient clinic.

Results-Sixty patients (28 male, 32 female), median age 51 (18-75) with chronic knee synovitis were studied. Diagnoses included: rheumatoid arthritis $(n=29)$; psoriatic arthritis $(\mathrm{n}=9)$; ankylosing spondylitis $(n=3)$; reactive arthritis $(n=2)$; undifferentiated seronegative oligoarthritis $(n=13)$ and miscellaneous inflammatory conditions $(n=4)$. More patients who received Sm-153 PHYP/triamcinolone hexacetonide sustained clinical benefit a year after treatment compared with patients who received corticosteroid alone (12 of $31(39 \%) v 6$ of $29(21 \%)$, a difference of $18 \%$ more patients $(95 \%$ CI $-5 \%$ to $41 \%)$ ) though the difference was not significant $\left(\chi^{2}=2.31,0.2>p>0.1, n=60\right)$. Despite the variation in injected activity (median $563 \mathrm{MBq}$, range 218-840 MBq), there was no obvious relation between low levels of injected activity $(<555 \mathrm{MBq})$ and relapse within 12 months of treatment $\left(\chi^{2}\right.$ $=2.61,0.2>$ p $>0.1, n=31$ ).

Conclusions-There was no clear beneficial clinical effect of combined Sm-153 PHYP/triamcinolone hexacetonide injection over triamcinolone hexacetonide alone a year after treatment for chronic knee synovitis.

(Ann Rheum Dis 1999;58:554-558)

Radiation synovectomy is one of several local treatments for chronic synovitis, which include glucocorticoid injection, saline irrigation, chemical or surgical synovectomy. All procedures have potential disadvantages. For exam- ple, patients may develop reduced range of movement after open synovectomy, ${ }^{1}$ arthroscopic synovectomy is technically demanding and highly operator dependent, ${ }^{2}$ chemical synovectomy can be a painful procedure and may cause cartilage damage, ${ }^{34}$ and, despite only a few published case reports, ${ }^{5-7}$ concerns remain about the incidence of malignancy after radiation synovectomy. The development of yttrium-90 (Y-90) colloids was primarily a response to the concerns about the high levels of extra-articular leakage of gold-198 (Au-198) after Au-198 colloid joint injection. ${ }^{8}$ However, both radiopharmaceuticals have been associated with extra-articular activity levels that correlate with chromosome damage manifest by an increase in specific chromosomal aberrations. ${ }^{10-12}$ Leakage of radioactivity from a joint can be reduced by both immobilisation of the joint after the procedure and injection of glucocorticoid with the radiopharmaceutical. ${ }^{13}{ }^{14}$ Randomised controlled trials comparing Y-90 colloids with placebo or other treatments have been limited and do not show clear evidence for their efficacy. ${ }^{15}$ A multicentre trial attempted to resolve this question by comparing Y-90 with triamcinolone hexacetonide but the target patient number was not reached because of problems with recruitment. ${ }^{16}$ Furthermore, published data show no difference in efficacy between radiation and surgical synovectomy, ${ }^{17}$ radiation and chemical synovectomy ${ }^{18}$ and chemical and surgical synovectomy. ${ }^{19}$

New radiopharmaceuticals would ideally be safe, implying an ability to be highly retained within joints, and efficacious when compared with alternative treatments. Samarium-153 particulate hydroxyapatite (Sm-153 PHYP) is stable and remains tightly bound in vivo. ${ }^{20}$ Clinical trials confirm that extra-articular escape of Sm-153 PHYP compares favourably with Y-90 colloids as $<1 \%$ of injected activity is detectable outside the knee. ${ }^{21}$ The extraarticular whole body radiation (unwanted) dose is approximately $3.8 \mathrm{mSv}$, which is no more than the estimated dose from an isotope bone scan (3.7-6 mSv). ${ }^{22}$ This dose is significantly lower than the dose estimated from Y-90 synovectomy and similar to the dose after intra-articular dysprosium-165 macroaggregates, ${ }^{23}$ another radiopharmaceutical currently available. There is no evidence for an increase in chromosome-type damage after Sm-153 PHYP therapy. ${ }^{23 a}$ There are additionally no local side effects or clinically observed unwanted effects from the injection of the 
particulate hydroxyapatite (diameter range 5-45 $\mu \mathrm{m}$ ) up to a year after injection. ${ }^{24}$ Chemical and physical characteristics of Sm-153 PHYP are included in appendix 1.

The aim of this study was to compare symptomatic outcome in a cohort of patients with chronic knee synovitis at one year after treatment with either Sm-153 PHYP combined with triamcinolone hexacetonide $(\mathrm{TH})$ or $\mathrm{TH}$ injection alone. The study was conducted according to a double blind, randomised controlled, intention to treat design.

\section{Methods}

PATIENTS

Patients were referred from rheumatology departments in the Greater London region. Patients were recruited if they were age 18 or over, had had synovitis of the knee for at least two years, which, on clinical review, was causing pain and/or stiffness that limited their mobility. Current medication, including oral glucocorticoids, was recorded. Exclusion criteria were: pregnant or breast feeding women; patients who had had either a change in their slow acting anti-rheumatic drugs (SAARDs) or their dose, or any intra-articular therapy in the study knee in the previous three months; less than $2 \mathrm{~mm}$ in either tibiofemoral joint space measured with a ruler on weightbearing radiographs. Informed written consent was obtained. Ethical approval was obtained from the University College London Medical School Clinical Investigations Panel.

\section{PROCEDURE}

Patients were randomised by the radiopharmacist to receive approximately $555 \mathrm{MBq}$ (15mCi) Sm-153 PHYP with $40 \mathrm{mg} \mathrm{TH}$ or $\mathrm{TH}$ alone. The procedure was performed by an investigator, blinded to the randomisation, in an outpatient setting in the Institute of Nuclear Medicine. All women of childbearing age had to have a negative pregnancy test before proceeding with the study injection. The knee was drained using a 21 gauge needle. The injection apparatus, which was covered by tape, consisted of a three way tap attached to a small syringe containing Sm-153 PHYP/TH or TH in a $3-5 \mathrm{ml}$ volume. The drug was injected and the syringe and three way tap flushed three times by drawing in a total of $5 \mathrm{ml}$ of saline from a reservoir attached to the side port of the three way tap. After withdrawing the needle, the knee was passively flexed twice to augment intra-articular distribution of injected drugs and injection apparatus returned to radiopharmacy for activity analysis. ${ }^{21}$ The knee was splinted in a semi-rigid splint for four hours after the procedure. Transport home was provided and the patients advised to rest at home for the subsequent 24 hours.

PRIMARY CLINICAL OUTCOME

A simple measure of outcome, termed symptom score $(0,1$ or 2$)$, was chosen as primary outcome to reflect chronic knee synovitis symptom severity and consequent functional impairment. The scores were: $2=$ knee pain and/or stiffness limiting mobility; $1=$ knee pain
Table 1 Clinical details at baseline

\begin{tabular}{|c|c|c|}
\hline Clinical details & $\begin{array}{l}\text { Sm-153 } \\
\text { PHYP/TH } \\
(n=31)\end{array}$ & $\begin{array}{l}\text { TH alone } \\
(n=29)\end{array}$ \\
\hline Mean age (SD) & $46(14)$ & $51(14)$ \\
\hline Age range & $24-72$ & $17-75$ \\
\hline Male/female & $15 / 16$ & $13 / 16$ \\
\hline \multicolumn{3}{|l|}{ Diagnosis } \\
\hline Rheumatoid arthritis & 13 & 16 \\
\hline Psoriatic arthritis & 3 & 6 \\
\hline Ankylosing spondylitis & 1 & 2 \\
\hline Reactive arthritis & 2 & 0 \\
\hline Undifferentiated ${ }^{\star}$ & 10 & 3 \\
\hline Othert & 2 & 2 \\
\hline $\begin{array}{l}\text { Number of previous knee joint } \\
\text { corticosteroid injections (range) }\end{array}$ & $4(1-15)$ & $4(2-20)$ \\
\hline $\begin{array}{l}\text { Median number of months since last } \\
\text { knee joint corticosteroid injection } \\
\text { (range) }\end{array}$ & $5(3-24)$ & $6(3-36)$ \\
\hline $\begin{array}{l}\text { Median number of years of disease } \\
\text { duration (range) }\end{array}$ & $8(2-32)$ & $8(2-30)$ \\
\hline \multicolumn{3}{|l|}{ Number of patients taking } \\
\hline SAARDs & 17 & 18 \\
\hline NSAIDs & 27 & 20 \\
\hline
\end{tabular}

$\star$ Undifferentiated rheumatoid factor seronegative oligoarthritis. †Polyarteritis nodosa (1); juvenile chronic arthritis (1); sarcoid (1); Sjögren's syndrome (1).

and/or stiffness not affecting mobility; $0=$ no pain or stiffness. The scores were recorded during the clinical review at baseline and at 3, 6, 9 and 12 months after treatment by an investigator blinded to the randomisation code. According to entry criteria, therefore, all patients scored 2 at entry to the study.

\section{CLINICAL REVIEW}

At baseline clinical and follow up clinical review (3, 6, 9 and 12 months) the following measures were also recorded: joint tenderness and swelling using a modified Ritchie score ${ }^{25}$; knee circumference ${ }^{26}$; range of movement (degrees); full blood count (FBC); erythrocyte sedimentation rate (ESR). Patients were unblinded from the study if they had relapsed at any follow up visit or after 12 months. Criteria for relapse were: a symptom score of 2 (thus reflecting the need for further intervention) or having received intra-articular glucocorticoid into the study knee from the patient's rheumatologist in the period between reviews (thus implying a symptom score of 2 in the interim). Changes in systemic treatment, including dose alteration, were recorded at each visit but not considered to indicate relapse. Patients who had relapsed in under 12 months and had not received Sm-153 PHYP were offered it on an open basis.

Table 2 Symptom scores at intervals up to a year after treatment

\begin{tabular}{|c|c|c|c|c|}
\hline \multirow{2}{*}{$\begin{array}{l}\text { Time after } \\
\text { treatment } \\
\text { (months) }\end{array}$} & \multicolumn{2}{|c|}{$\begin{array}{l}\text { Symptom score }{ }^{\star} \text { in } \\
\text { number }(\%) \text { patients } \\
\text { treated with Sm-153 } \\
\text { PHYP + TH }(n=31)\end{array}$} & \multicolumn{2}{|c|}{$\begin{array}{l}\text { Symptom score }{ }^{*} \text { in } \\
\text { number }(\%) \text { patients } \\
\text { treated with TH alone } \\
(n=29)\end{array}$} \\
\hline & Score 0/1 & Score 2 & Score $0 / 1$ & Score 2 \\
\hline 3 & $21(68)$ & $10(32)$ & $19(66)$ & $10(34)$ \\
\hline 6 & $16(52)$ & $15(48)$ & $11(38)$ & $18(62)$ \\
\hline 9 & $13(42)$ & $18(58)$ & $7(24)$ & $22(76)$ \\
\hline 12 & $12(39)$ & $19(61)$ & $6(21)$ & $23(79)$ \\
\hline
\end{tabular}

*Symptom scores: $2=$ knee pain and/or stiffness limiting mobility; 1 = knee pain and/or stiffness not affecting mobility; $0=$ no knee pain or stiffness. 
Table 3 Clinical and laboratory measures before treatment (baseline) and at three monthly intervals after treatment with either Sm-153 PHYP + TH or TH alone

\begin{tabular}{|c|c|c|c|c|c|c|}
\hline $\begin{array}{l}\text { Clinical or laboratory measure } \\
(\text { mean }(S D))\end{array}$ & & Baseline & 3 months & 6 months & 9 months & 12 months \\
\hline \multirow[t]{3}{*}{ Knee flexion range $\left(^{\circ}\right)$} & Sm-153 PHYP +TH & $\begin{array}{l}112(16) \\
n=31\end{array}$ & $\begin{array}{l}126(17) \\
\mathrm{n}=29\end{array}$ & $\begin{array}{l}128(17) \\
\mathrm{n}=18\end{array}$ & $\begin{array}{l}131(16) \\
n=13\end{array}$ & $\begin{array}{l}133(16) \\
n=10\end{array}$ \\
\hline & TH & $113(15)$ & $121(25)$ & $129(15)$ & $126(15)$ & $135(15)$ \\
\hline & & $\mathrm{n}=29$ & $\mathrm{n}=28$ & $\mathrm{n}=19$ & $\mathrm{n}=10$ & $\mathrm{n}=7$ \\
\hline \multirow[t]{4}{*}{ Knee circumference $(\mathrm{cm})$} & Sm-153 PHYP +TH & $41(4)$ & $41(4)$ & $40(4)$ & $39(3)$ & $41(4)$ \\
\hline & & $\mathrm{n}=31$ & $\mathrm{n}=29$ & $\mathrm{n}=18$ & $\mathrm{n}=13$ & $\mathrm{n}=10$ \\
\hline & $\mathrm{TH}$ & $41(4)$ & $39(4)$ & $38(3)$ & $39(4)$ & $38(2)$ \\
\hline & & $\mathrm{n}=29$ & $\mathrm{n}=22$ & $\mathrm{n}=19$ & $\mathrm{n}=10$ & $\mathrm{n}=7$ \\
\hline \multirow{4}{*}{$\begin{array}{l}\text { Swollen joint count (scored } \\
\text { out of } 34 \text { ) }\end{array}$} & Sm-153 PHYP +TH & $4(3)$ & $3(3)$ & $3(3)$ & $4(5)$ & $3(3)$ \\
\hline & & $\mathrm{n}=31$ & $\mathrm{n}=29$ & $\mathrm{n}=18$ & $\mathrm{n}=13$ & $\mathrm{n}=10$ \\
\hline & TH & $4(4)$ & $0(0.5)$ & $4(4)$ & $3(2)$ & $3(3)$ \\
\hline & & $\mathrm{n}=28$ & $\mathrm{n}=28$ & $\mathrm{n}=19$ & $\mathrm{n}=10$ & $\mathrm{n}=7$ \\
\hline \multirow{4}{*}{$\begin{array}{l}\text { Ritchie score (pain score } \\
\text { out of } 34 \text { ) }\end{array}$} & Sm-153 PHYP +TH & $6(7)$ & $5(7)$ & $4(4)$ & $6(10)$ & $4(3)$ \\
\hline & & $\mathrm{n}=31$ & $\mathrm{n}=29$ & $\mathrm{n}=18$ & $\mathrm{n}=13$ & $\mathrm{n}=10$ \\
\hline & $\mathrm{TH}$ & $6(6)$ & $3(4)$ & $5(7)$ & $2(2)$ & $2(2)$ \\
\hline & & $\mathrm{n}=29$ & $\mathrm{n}=28$ & $\mathrm{n}=19$ & $\mathrm{n}=10$ & $\mathrm{n}=7$ \\
\hline \multirow[t]{4}{*}{ Haemoglobin (g/dl) } & Sm-153 PHYP +TH & $13.0(14)$ & $13.2(15)$ & $13.1(14)$ & $12.9(14)$ & $13.9(15)$ \\
\hline & & $\mathrm{n}=27$ & $\mathrm{n}=25$ & $\mathrm{n}=15$ & $\mathrm{n}=10$ & $\mathrm{n}=5$ \\
\hline & $\mathrm{TH}$ & $12.4(15)$ & $12.3(16)$ & $12.1(5)$ & $12.7(12)$ & $12.2(5)$ \\
\hline & & $\mathrm{n}=22$ & $\mathrm{n}=25$ & $\mathrm{n}=14$ & $\mathrm{n}=6$ & $\mathrm{n}=7$ \\
\hline \multirow[t]{4}{*}{ Platelets $\left(\times 10^{9} / \mathrm{mm}^{3}\right)$} & Sm-153 PHYP +TH & $293(73)$ & $315(90)$ & $309(85)$ & $282(74)$ & $261(75)$ \\
\hline & & $\mathrm{n}=27$ & $\mathrm{n}=25$ & $\mathrm{n}=15$ & $\mathrm{n}=10$ & $\mathrm{n}=5$ \\
\hline & $\mathrm{TH}$ & $339(96)$ & $361(148)$ & $390(195)$ & $350(184)$ & $347(74)$ \\
\hline & & $\mathrm{n}=22$ & $\mathrm{n}=25$ & $\mathrm{n}=14$ & $\mathrm{n}=6$ & $\mathrm{n}=7$ \\
\hline \multirow[t]{4}{*}{ ESR (mm 1st h) } & Sm-153 PHYP + TH & $32(27)$ & $37(32)$ & $32(28)$ & $33(27)$ & $18(18)$ \\
\hline & & $\mathrm{n}=27$ & $\mathrm{n}=25$ & $\mathrm{n}=14$ & $\mathrm{n}=10$ & $\mathrm{n}=7$ \\
\hline & $\mathrm{TH}$ & $47(34)$ & $44(32)$ & $52(36)$ & $38(40)$ & $56(32)$ \\
\hline & & $\mathrm{n}=22$ & $\mathrm{n}=25$ & $\mathrm{n}=14$ & $\mathrm{n}=5$ & $\mathrm{n}=7$ \\
\hline
\end{tabular}

$\mathrm{n}=$ the number of patients for whom data were available at that time.

\section{STATISTICAL METHODS}

The number of patients who had relapsed in each group was compared at 12 months after treatment using $\chi^{2}(2 \times 2)$ test. A sample size of 60 was estimated to be necessary to allow detection of a $30 \%$ difference in relapse (score 2) between the two groups with $95 \%$ confidence. This difference in relapse rate was taken to denote a clinically useful benefit. The relation between injected Sm-153 activity and relapse at 12 months and was also examined using a $\chi^{2}$ test.

\section{Results}

Sixty five patients were recruited. Three patients withdrew before treatment. Injection of one patient was aborted as intra-articular needle access could not be confidently confirmed and a further patient withdrew three months after treatment because of difficulty attending follow up and deteriorating cardiovascular health. Sixty patients were included in the final analysis ( 28 men, 32 women). Table 1 shows the baseline characteristics.

Of the patients who received Sm-153 PHYP/ $\mathrm{TH}, 19$ of $31(61 \%)$ had relapsed within 12 months whereas 23 of $29(79 \%)$ of those treated with $\mathrm{TH}$ alone had relapsed (table 2). The difference was not significant $\left(\chi^{2}=2.31\right.$, $0.2>p>0.1, n=60)$. However, more patients had sustained a benefit (symptom score 0 or 1 ) from combined treatment compared with triamcinolone hexacetonide alone at a year $(18 \%$ more patients, $95 \% \mathrm{CI}-5 \%$ to $41 \%$ ) and consistently at three monthly intervals up to a year after treatment (table 2). Table 3 shows baseline and follow up clinical and laboratory indices in the two treatment groups. There appeared to be an improvement in knee flexion from baseline measurements in both groups. There were no obvious trends in the other clinical parameters over time during the study. Subgroup clinical symptom score analysis according to diagnosis was not undertaken; however, there was no obvious difference in the response to treatment between different diagnostic groups. Of the undifferentiated seronegative oligoarthritis patients two of three in the $\mathrm{TH}$ alone group had relapsed at one year, compared with 7 of 10 in the Sm-153 PHYP/TH group.

Median injected activity of Sm-153 was 563 $\mathrm{MBq}$ (range 218-840 MBq), which represented between $35-95 \%$ of prepared activity. Low levels of injected activity occurred resulting from particulate hydroxyapatite getting caught in the needle hub during the injection procedure. Injected activity did not appear to be related to operator experience. There was no obvious association between injected activity $(<555 \mathrm{MBq}$ or $>555 \mathrm{MBq})$ and relapse within a year of treatment $\left(\chi^{2}=2.61\right.$, $0.2>\mathrm{p}>0.1, \mathrm{n}=31$ ).

\section{Discussion}

In this group of patients with various diagnoses, there appeared to be no significant additional clinical effect from injecting both Sm-153 PHYP combined with $40 \mathrm{mg} \mathrm{TH}$ compared with injecting $40 \mathrm{mg} \mathrm{TH}$ alone for knee synovitis. However, the data show that consistently fewer patients relapsed (or more sustained benefit) after combined treatment notably after a year (18\% of patients) but also at each interim analysis (see table 2 ). This suggests that there is likely to be a therapeutic effect from Sm-153 PHYP though perhaps smaller than anticipated. The failure to demonstrate a significant effect compared with injected corticosteroid may have been a consequence of the power of the study.

A number of features in this study are worthy of discussion: the use of Sm-153 PHYP as a radiopharmaceutical, the variability of injected intra-articular activity of Sm-153 PHYP and 
the inclusion of several different diagnostic groups.

The safety of Sm-153 PHYP is supported by the low levels of unwanted extra-articular escape of activity from the joint ${ }^{21}$ and the absence of any increase in chromosomal aberrations after treatment with this radiopharmaceutical. ${ }^{23 a}$ Sm-153 PHYP has been shown to be stable in vitro, the labelling procedure is efficient and reproducible and its half life allows time for transportation. ${ }^{20}$ No local side effects have been observed though almost 100 patients have been treated. Although Sm-153 PHYP has a relatively short maximum tissue penetration compared with other radioisotopes used for synovectomy of the knee $(3.1 \mathrm{~mm}$ compared with $10 \mathrm{~mm}$ for Y-90), it is distributed throughout the synovial lining, ${ }^{20}{ }^{27}$ suggesting that deeper layers of the synovial subintima will be irradiated.

It has been evident from previous data that the Sm-153 PHYP sediments within the syringe, ${ }^{21}$ and although in our protocol the injection apparatus was flushed thoroughly in an attempt to reduce sedimentation, the injected activity was variable. Injected activity did not improve with increasing operator experience. By reducing the mean size and size range of particles, the potential for sedimentation of hydroxyapatite particles has now been reduced (James Brodack, personal communication). However, there was no clear relation between injected activity and relapse, suggesting against a major dose response effect and in keeping with the findings from an open study of clinical outcome. ${ }^{24}$ To explore a dose response relation further, information could have been obtained from post-injection imaging, as previously described, ${ }^{21}$ and findings compared with clinical outcome. However, the methodology was optimised to maintain "blinding" of both operator and patient and any attempts at imaging could have undermined this. We would recommend that any further investigations of Sm-153 PHYP, possibly in smaller joints, should include evaluation of a relation between injected activity and outcome.

Predicted recruitment rates and considerations of statistical power required pooling of diagnostic groups; however, could the variation in underlying disease have influenced the outcome? Probably not, as the range of diagnoses, historical features of the disease and treatment was broadly comparable in the two treatment groups (table 1), and there were no substantial differences in the clinical and laboratory indices of disease at baseline (table 2). We would, therefore, conclude that there is no clear variation in response between diagnostic groups.

In summary, our data suggest that in this group of patients with various diagnoses there is no sustained therapeutic effect from combining Sm-153 PHYP radiation synovectomy with injection with $40 \mathrm{mg} \mathrm{TH}$ for knee synovitis compared with injecting $40 \mathrm{mg} \mathrm{TH}$ alone. However, our data do not suggest against a therapeutic effect from Sm-153 PHYP. Given its favourable physical and radiobiological properties, further studies with Sm-153 PHYP will be worthwhile; however, it will be important to consider carefully whether less of a difference, in clinical outcome between Sm-153 PHYP and injected long acting corticosteroid, than we have considered here, should be regarded as clinically useful in the context of balancing relative risk:benefit and cost effectiveness of the two treatments.

\section{Appendix 1}

Physical and biological data of Sm-153 and particulate hydroxyapatite

Physical characteristics of Sm-153 (All data from Raddecay, Grove engineering Inc, 1987); half life 46.3 hours; mean $\beta^{-}$decay range $=0.081-0.263 \mathrm{MeV} ;$ most abundant $\beta$ - energies (\% total) $=0.199 \mathrm{MeV}(34 \%)$, $0.224 \mathrm{MeV}(44 \%), 0.263 \mathrm{MeV}(21 \%) ; \beta$ penetration in soft tissue $=3.1 \mathrm{~mm}$ (maximum) $/ 0.7 \mathrm{~mm}\left(\mathrm{x}_{0}{ }^{\star}\right) ;$ most abundant $\gamma$ energies $(\%$ total $)=0.041 \mathrm{MeV}(17 \%)$, $0.042 \mathrm{MeV}(31 \%), 0.103 \mathrm{MeV}(28 \%)$. Particulate hydroxyapatite (PHYP) size range $=5-45 \mu \mathrm{m}$ diameter.

${ }^{\star} \mathbf{X}_{90}$ is the therapeutic range $(\mathrm{mm})$ of $\beta^{-}$decay and is defined as the depth in synovium by which $90 \%$ of the dose from $\beta^{-}$particles, present at the surface of the tissue, has been absorbed. ${ }^{28}$

1 Camp VA. Synovectomy of the knee in rheumatoid arthritis. Range of movement and quadriceps lag after surgery. Ann Rheum Dis 1972;31:155-8.

2 Highgenboten CL. Arthroscopic synovectomy. Orthop Clin North Am 1982;13:399-405.

3 Nissilä M, Ahlqvist Y, Collan Y, Raunio P, Isomäki H. Morphological findings in joint cartilage after osmic acid treatment. Scand J Rheumatol 1977;5:231-6.

4 Niculescu D, Tomescu E, Ionescu C, Cotutiu C, Hvisanidi $\mathrm{S}$, Negoescu $\mathrm{M}$, et al. Ultrastructural changes in cartilage after intra-articular administration of osmium tetroxide and the sodium salts of fish oil fatty acids (varicocid). Scand J Rheumatol 1976;5:133-40.

5 Lipton JH, Messner HA. Chronic myeloid leukemia in a woman with Still's disease treated with Au-198 synoviorthesis. J Rheumatol 1991;18:734-5.

6 Goh K, Jacox RF, Anderson FW. Chromosomal abnormalities. Findings in a patient with lymphoma and rheumatoid arthritis treated with intra-articular ${ }^{198} \mathrm{Au}$. Arch Pathol Lab Med 1980;104:473-5.

7 Menkes CJ. Is there a place for chemical and radiation synovectomy in rheumatic diseases? Rheumatol Rehabil 1979 18:65-77.

8 Virkunnen M, Krusius FE, Heiskanen T. Experiences of intra-articular administration of radioactive gold. Acta Rheum Scand 1967;13:81-91.

9 Ingrand J. Characteristics of radio-isotopes for intraarticular therapy. Ann Rheum Dis 1973;32:3-9.

10 Stevenson AC, Bedford J, Dolphin GW, Purrott RJ, Lloyd DC, Hill AGS, et al. Cytogenetic and scanning study of patients receiving intra-articular injections of gold-198 and patients receiving intra-articular injections of gol

11 Doyle DV, Glass JS, Gow PJ, Daker M, Grahame R. A clinical and prospective chromosomal study of yttrium-90 synovectomy. Rheumatol Rehabil 1977;16:217-22.

12 Jalava S, Salonius AL. Chromosomes of patients treated with yttrium-90. Lancet 1974;i:807.

13 Williams PL, Crawley JCW, Freeman AM, Lloyd DC, Gumpel JM. Feasibility of out-patient management after intra-articular yttrium-90: comparison of two regimes. BMJ 1981;282:13-14

14 Goode JD, Howey S. Effect of premedication with intra-articular hydrocortisone on the retention of ${ }^{198} \mathrm{Au}$ in the knee joint in rheumatoid arthritis. Ann Rheum Dis 1973;32:43-4.

15 Jones G. Yttrium synovectomy: a meta-analysis of the literature. Aust NZ J Med 1993;23:272-5.

16 Arthritis and Rheumatism Council Multicentre Radiosynoviorthesis trial group. Intra-articular radioactive yttrium oviorthesis trial group. Intra-articular radioactive yttrium and triamcinolone hexaceto

17 Gumpel JM, Roles NC. A controlled trial of intra-articular radiocolloids versus surgical synovectomy in persisten synovitis. Lancet 1975;i:488-9.

18 Sheppeard H, Aldin A, Ward DJ. Osmic acid versus yttrium-90 in rheumatoid synovitis of the knee. Scand J Rheumatol 1981;10:234-6.

19 Nissilä M, Anttila P, Hämäläinen M, Jalava S. Comparison of chemical, radiation and surgical synovectomy for knee joint synovitis. Scand J Rheumatol 1978;7:225-8.

20 Chinol M, Vallabhajosula S, Goldsmith SJ, Klein MJ, Deutsch KF, Chinen LK, et al. Chemistry and biological : potential radiopharmaceuticals (1993;34:1

21 Clunie G, Lui D, Cullum I, Edwards JCW, Ell PJ. Samarium-153-particulate hydroxyapatite radiation synovectomy: Biodistribution data for chronic knee synovitis. J Nucl Med 1995;36:51-7. 
22 Shields RA, Lawson RS. Effective dose equivalent. Nucl Med Commun 1987;8:851-5.

23 Deutsch E, Brodack JW, Deutsch KF. Radiation synovectomy revisited. Eur J Nucl Med 1993;20:1113-27.

23a O'Duffy EK, Oliver FJ, Chatters SJ, Walker H, Lloyd DC Edwards JCW, et al. Chromosomal analysis of periphera lymphocytes of patients before and after radiation synorectomy with samarium-153 particulate hydroxyapatite. Rheumatology 1999;38:316-20.

24 Clunie G, Lui D, Cullum I, Ell PJ, Edwards JCW. Clinical outcome after one year following samarium-153 particulate hydroxyapatite radiation synovectomy. Scand J Rheumatol 1996;25:360-6.
25 Ritchie DM, Boyle JA, McInnes JM, et al. Clinical studies with an articular index for the assessment of join tenderness in patients with rheumatoid arthritis. Q J Med 1968; 147:393-406

26 Kirwan JR, Byron MA, Winfield J, Altman DG, Gumpel $J M$. Circumferential measurements in the assessment of synovitis of the knee. Rheumatol Rehabil 1979;18:78-84.

27 Shortkroff S, Mahmood A, Sledge CB, et al. Studies on Ho-166-labeled hydroxyapatite: a new agent for radiation synovectomy. [Abstract]. J Nucl Med 1992;33:937.

28 Johnson LS, Yanch JC, Shortkroff S, Barnes CL, Spitzer AI, Sledge CB. Beta-particle dosimetry in radiation synovectomy. J Nucl Med 1995;22:977-88.

$\frac{1}{3}$ 